\title{
CERVICAL VIRAL INFECTIONS AMONG ASYMPTOMATIC BULGARIAN WOMEN
}

\author{
Jeni Staykova ${ }^{1,2}$, Tanja Belovska ${ }^{1}$, Ayla Murad ${ }^{1}$, Sevinch Kakid ${ }^{1}$, Aneta Nacheva ${ }^{3}$, Evelina Shikova ${ }^{4}$ \\ ${ }^{1}$ Regional Health Inspectorate, Kardzhali, Bulgaria \\ ${ }^{2}$ Faculty of Public Health, Medical University, Sofia, Bulgaria \\ ${ }^{3}$ Military Medical Academy, Sofia, Bulgaria \\ ${ }^{4}$ National Centre of Infectious and Parasitic Diseases, Sofia, Bulgaria
}

\begin{abstract}
SUMMARY
Aim: Although sexually transmitted viral infections are significant and increasing public health concern, little is known about their prevalence among Bulgarian women. The aim of this study was to investigate cervical viral infections in asymptomatic women.

Methods: The study group included 52 randomly selected asymptomatic female volunteers from Bulgarian border town Kardzhali. Cervical specimens were tested by real-time PCR for human papillomaviruses (HPV), herpes simplex virus (HSV) types 1 and 2, cytomegalovirus (CMV), Epstein-Barr virus (EBV), and human immunodeficiency virus (HIV).

Results: The investigation demonstrated a high rate $(61.5 \%)$ of infection with one or more viruses of uterine cervix of participating women considered at low risk. The most prevalent was HPV, found in $32.7 \%$ of all women. The genotyping of high-risk (HR) HPV positive specimens showed that HPV16 was the most prevalent HR type. HSV prevalence (30.8\%) was almost as high as that of HPV and most women were HSV1 infected. $9.6 \%$ and $5.8 \%$ of all specimens were positive for EBV and CMV, respectively.

Conclusions: Our results indicate that women from Kardzhali region, involved in this study, might be at risk for development of genital tract pathology, including cervical cancer, and for transmission of virus infection sexually and perinatally.
\end{abstract}

Key words: women's health issues, viral infections, cervix, RT PCR, Bulgaria

Address for correspondence: E. Shikova, Department of Virology, National Centre of Infectious and Parasitic Diseases, General Stoletov Str. 44A, 1233 Sofia, Bulgaria. E-mail: evelina_sh@abv.bg

http://dx.doi.org/10.21101/cejph.a4299

\section{INTRODUCTION}

The incidence of viral sexually transmitted infections (STI) has increased considerably in recent years. Genital human papillomaviruses (HPV) are the most common STI and the main cause of cervical cancer. At the same time, most infections with HPV do not lead to cervical pathology. Therefore, it was suggested that additional co-factors, including co-infection with other sexually transmitted viruses, are required for progression of cervical HPV infection to cervical cancer. Some studies have shown that herpes simplex virus (HSV), cytomegalovirus (CMV), EpsteinBarr virus (EBV), human immunodeficiency virus (HIV) could be co-factors of HPV-associated carcinogenesis (1-3). Although the majority of herpesvirus infections in women are asymptomatic, these viruses could be responsible for clinically apparent genital infections, sometimes leading to complications, such as endometritis, pelvic inflammatory disease and salpingitis. HIV and some members of herpesvirus family are major cause of congenital or neonatal infections. Although viral STI are a significant and increasing public health concern, relatively little is known about their prevalence among Bulgarian women. The purpose of this study was to determine the prevalence of HPV, HSV types 1 and 2, CMV, EBV and HIV in cervical specimens, obtained from asymptomatic Bulgarian women.

\section{MATERIALS AND METHODS}

\section{Study Participants}

The study involved 52 randomly selected asymptomatic female volunteers from Bulgarian border town Kardzhali of median age 39 years (range 17-57 years). They were asked to complete a standard questionnaire to collect data on demographics, reproductive health, cervical cancer screening history, use of contraceptives, and smoking status. The basic characteristics of the study group are shown in Table 1. Informed consent for participation in the study was obtained from all participants. The study protocol was approved by the Ethical Committee at the Bulgarian Medical Association, Kardzhali Region (Approval No. 02/03.05.2013). Cervical specimens were taken from all women by cytobrush and collected in PreservCyt solution (Hologic) for virological investigations.

\section{Nucleic Acid Extraction}

The virus DNA and RNA were extracted from cervical specimens using MicroElute Viral RNA/DNA extraction kit (Cat. No: R6974-01, Omega Bio-tek USA) and DNA-sorb-B nucleic acid extraction kit (Cat. No: K1-2-100-CE, Ecoli, Bratislava, Slovak 
Table 1. Characteristics of the study participants $(N=52)$

\begin{tabular}{|l|c|}
\hline Characteristic & $\mathbf{n}(\%)$ with characteristic \\
\hline 35 years or older & $33(63.5)$ \\
\hline Married & $38(73.0)$ \\
\hline With pregnancy history & $43(82.7)$ \\
\hline Smokers & $31(59.6)$ \\
\hline Regular Pap testing & $35(67.3)$ \\
\hline Abnormal Pap test in the past & $1(2.0)$ \\
\hline Condom use & $14(27)$ \\
\hline Oral contraceptive use & 0 \\
\hline
\end{tabular}

Republic) according to the instructions provided by the manufacturers.

\section{Real-time PCR Amplification}

Each cervical sample was analyzed by real-time (RT) PCR for the presence of high-risk (HR) HPV, low-risk (LR) HPV, HSV type 1 and type 2, CMV, EBV and HIV. In addition, genotyping of HPV positive samples was performed. The following commercial kits for virus testing by RT PCR were used: AmpliSens ${ }^{\circledR}$ HPV HCR-screen-titre-FRT PCR kit (Cat. No: R-V31-T-4x-CE, Ecoli, Bratislava, Slovak Republic) for detection (without exact genotype detecting) the HPV DNA of two main phylogenetic groups - A7, A9, which include the HPV types 16, 18, 31, 33, $35,39,45,52,58,59$ as well as the HPV DNA 51 (A5 group) and 56 (A6 group) types; AmpliSens ${ }^{\circledR}$ HPV HCR-genotype-FRT PCR kit (Cat. No: R-V25-CE, Ecoli, Bratislava, Slovak Republic) for detection and differentiation of high carcinogenic risk (HCR) HPV types 16, 18, 31, 33, 35, 39, 45, 51, 52, 56, 58, 59 DNA; AmpliSens ${ }^{\circledR}$ HPV 6/11-FRT PCR kit (Cat. No: R-V11-CE, Ecoli, Bratislava, Slovak Republic) for detection and differentiation of LR HPV types 6 and 11; AmpliSens ${ }^{\circledR}$ HSV-typing-FRT PCR kit (Cat. No: R-V38-F(RG,iQ)-CE, Ecoli, Bratislava, Slovak Republic) for detection and typing of HSV types 1 and 2 DNA; AmpliSens ${ }^{\circledR}$ HIV-Monitor-FRT Kit (Cat. No: R-V0-M-CE, Ecoli, Bratislava, Slovak Republic) for reverse transcription and quali- tative detection and quantification of HIV-1RNA; AccuPower ${ }^{\circledR}$ CMV Quantitative PCR Kit (Cat. No: CMV-1111, Bioneer Corp., South Korea) for detection and quantification of CMV DNA; and AccuPower ${ }^{\circledR}$ EBV Quantitative PCR Kit (Cat. No: EBV-1111, Bioneer Corp., South Korea) for detection and quantification of EBV DNA. In the studies all stages were performed according to the instruction manual of the particular Ecoli or Bioneer amplification kit. All amplifications were carried out in Exicycler ${ }^{\mathrm{TM}}$ 96 thermocycler from Bioneer (Bioneer Corp., South Korea).

\section{RESULTS}

Fifty-two cervical specimens, obtained from asymptomatic women from Bulgarian border town Kardzhali, were analysed by RT PCR to assess the presence of high- and low-risk HPV, HSV types 1 and 2, CMV, EBV and HIV. Our results showed that 32 $(61.5 \%)$ women were infected with one or more viruses. Of all 52 studied samples 17 (32.7\%) were positive for HPV (HR and/ or LR), 16 (30.8\%) were HSV1 and 2 positive, 5 (9.6\%), and 3 (5.8\%) samples were positive for EBV and CMV, respectively. None of the cervical samples were HIV positive. HPV prevalence among women aged 35 or younger was about 2.5 times higher than in older women. EBV and CMV were found only in cervical samples obtained from women older than 35 years. HSV prevalence was similar in both age groups. Most of the women were HSV1 infected, HSV2 was detected in only one cervical sample (Table 2).

Multiple infections were detected in $9(28 \%)$ of 32 positive women. Most of them (8 samples) were double infections whilst triple infection (HPV/EBV/CMV) was shown in only one case. Double infections HPV and HSV1 were detected most frequently (5 samples), followed by HPV/EBV, HPV/CMV and HSV1/EBV co-infections in 1 sample each.

Of all $17 \mathrm{HPV}$ positive cases $10(\mathrm{~N}=52,19.2 \% ; \mathrm{N}=17,58.8 \%)$ were HR HPV positive, $6(\mathrm{~N}=52,11.5 \% ; \mathrm{N}=17,35.3 \%) \mathrm{LR}$ HPV positive, and $1(\mathrm{~N}=52,1.9 \% ; \mathrm{N}=17,5.9 \%)$ sample was infected with both, HR HPV and LR HPV. HPV6 was the only LR HPV detected genotype. After genotyping of all HR HPV positive samples the following HR HPV genotypes were found: HPV16 was the most common HR HPV genotype, detected in

Table 2. Virus prevalence in cervical samples

\begin{tabular}{|l|c|c|c|}
\hline \multirow{2}{*}{ Viruses } & \multicolumn{2}{|c|}{ Positive samples } \\
\cline { 2 - 4 } & $\begin{array}{c}\text { All women (N=52) } \\
\mathbf{n}(\%) \text { positive* }\end{array}$ & $\begin{array}{c}\text { Women } \leq 35(\mathrm{~N}=19) \\
\mathrm{n}(\%) \text { positive }\end{array}$ & $\begin{array}{c}\text { Women >35 (N=33) } \\
\mathbf{n}(\%) \text { positive }\end{array}$ \\
\hline HPV, of them & $17(32.7)$ & $10(52.6)$ & $7(21.2)$ \\
\hline HR HPV & $10(19.2)$ & $6(31.6)$ & $4(12.1)$ \\
\hline LR HPV & $6(11.5)$ & $3(15.7)$ & $3(9.1)$ \\
\hline HR HPV + LR HPV & $1(1.9)$ & $1(5.3)$ & 0 \\
\hline HSV1/2, of them & $16(30.8)$ & $6(31.6)$ & $10(30.3)$ \\
\hline HSV1 & $15(28.8)$ & $6(31.5 \%)$ & $9(27.2)$ \\
\hline HSV2 & $1(1.9)$ & 0 & $1(3)$ \\
\hline EBV & $5(9.6)$ & 0 & $5(9.6)$ \\
\hline CMV & $3(5.8)$ & 0 & $3(5.8)$ \\
\hline HIV & 0 & 0 & 0 \\
\hline
\end{tabular}

*Total 32 (61.5\%) women were infected with one or more viruses. 
Table 3. Prevalence of HPV genotypes

\begin{tabular}{|l|c|c|c|}
\hline HPV genotypes detected & n of positive specimen & $\begin{array}{c}\text { \% of all specimens } \\
\mathbf{N}=52\end{array}$ & $\begin{array}{c}\text { \% of HPV positive specimens } \\
\mathbf{N}=17\end{array}$ \\
\hline HPV 6 & 7 & 13.5 & 41.2 \\
\hline HPV 16 & 5 & 9.6 & 29.4 \\
\hline HPV 18 & 1 & 1.9 & 5.9 \\
\hline HPV 31 & 2 & 3.8 & 11.8 \\
\hline HPV 51 & 2 & 3.8 & 11.8 \\
\hline HPV 52 & 1 & 1.9 & 5.9 \\
\hline HPV 56 & 2 & 3.8 & 11.8 \\
\hline HPV 59 & 1 & 1.9 & 5.9 \\
\hline HR HPV undetermined genotypes & 1 & 1.9 & 5.9 \\
\hline
\end{tabular}

5 samples $(\mathrm{N}=52,9.6 \% ; \mathrm{N}=17,29.4 \%)$, followed by HPV31, HPV 51 and HPV56 detected in 2 samples each $(\mathrm{N}=52,3.8 \%$; $\mathrm{N}=17,11.8 \%$ ), and HPV18, HPV 52 and HPV 59 in one sample each $(\mathrm{N}=52,1.9 \% ; \mathrm{N}=17,5.9 \%$ ) (Table 3). We were not able to determine any genotype in one HR HPV positive sample. HPV11, HPV33, HPV35, HPV39, HPV45 and HPV58 were not found. In 5 specimens $(\mathrm{N}=52,9.6 \% ; \mathrm{N}=17,29.4 \%)$ we detected co-infection with two HPV genotypes - four HR/HR genotypes and one HR/LR genotype.

\section{DISCUSSION}

In current study we demonstrated that $61.5 \%$ of cervical samples obtained from participating women were infected with one or more viruses. The most prevalent was HPV, found in $32.7 \%$ of all women. As the study group is considered at low risk (small town, older age, majority of women are married, etc.) it is not surprising that the overall HPV positivity among these women is lower than that previously detected in a high risk group of female sex workers (43.4\%) (4). At the same time, the HPV positivity in our study was about 2.5 times higher than the mean HPV prevalence among women from Central and Eastern Europe with normal cervical cytology (12.6\%), indicating a higher risk of cervical cancer (5). In accordance with previous data we found that younger women (age group $\leq 35$ ) were about 2.5 times more infected and that HPV16 was the most frequently (9.6\%) detected HR genotype among all women. We observed a very high prevalence of HPV6 (13.5\%).

HIV was not detected in any of cervical samples and this was not surprising given the low HIV positivity in the country. The overall HSV1/2 prevalence (30.8\%) in our study was almost as high as that of HPV. Moreover, the number of herpesvirus infected women in our study is most likely even higher, because as it is known from the literature, not all infected individuals shed the virus in their genital tract. The prevalence of HSV demonstrated in this study was higher than that previously described in cervical samples from other countries. Several studies investigated asymptomatic HSV shedding from the uterine cervix by PCR - the lowest rates (approximately 3\%) were observed in Turkey and Sweden and the highest in Argentina (21.5\%) and Brazil $(26 \%)(6-9)$. It was interesting that most cases in our study were HSV1 positive and only one was HSV2 positive. Although
HSV2 is considered one of the most common cause of genital ulceration, many studies indicate an increase in genital herpes caused by HSV1 (10-15). Our results support this trend. The high HSV positivity we observed in this study was in accordance with a previous seroepidemiological study of HSV1 and 2 in several European countries - the highest rates were found in Bulgaria (16). This is quite disturbing as HSV is implicated as an important cofactor of HPV infection and HPV-related cervical carcinogenesis (2). Bulgaria is one of the European countries with the highest incidence and mortality of cervical cancer (17), and it is possible that the high prevalence of genital HSV infection contributes to this situation.

Overall $9.6 \%$ and $5.8 \%$ of women in our study group were infected with EBV and CMV, respectively. Worldwide, EBV and CMV cervical positivity ranges from $2.6 \%$ to $40 \%$ and from $1.4 \%$ to $66 \%$, respectively $(7,9-10,18,19)$. Most of these studies utilized in-house PCR for identification of EBV and CMV. It is possible that methodological issues, such as PCR protocols or difference in sensitivity of PCR systems used for virus detection, may contribute to the observed variation of EBV/CMV prevalence in cervical samples between studies. In addition, this variation could be due to other factors - differences in sexual behaviour, geographical origin etc. According to the literature the highest rates of CMV (66\%) and EBV (40\%) cervical positivity were found among women with normal cervical smears attending cervical screening programme in Monza (Italy) and Aberdeen (UK), respectively $(19,20)$.

According to some previous studies EBV infection is more frequent in older women, but CMV prevalence decreases with age $(18,21)$. In our case EBV and CMV infections were found only in women older than 35 years. Our findings support the previous data concerning EBV and CMV cervical shedding and possibility of sexual transmission (22). It is not quite clear what is the clinical significance of these infections, including their role in cervical carcinogenesis. At the same time, EBV-associated genital ulcers in women have been previously reported $(23,24)$ and although CMV is not common cause of cervicitis, it is known as an important cause of congenital infection.

In conclusion, this investigation demonstrates a high rate of infection of uterine cervix with one or more viruses in participating women considered at low risk. Our results indicate that there is a high risk for genital pathology, including cervical cancer, and for transmission of virus infection sexually and perinatally. As far 
as we know, these are the first data for Bulgaria concerning HSV, EBV, CMV and HIV detection in cervical specimens and potential co-infection of these viruses with HPV. At the same time, there are some limitations of this study. Because the size of study group is small and all women come from one place, it is impossible to draw conclusions from these findings about Bulgarian women in general. In addition, given the cross-sectional nature of our study, the data do not exclude the possibility of spontaneous clearance of some of virus infections detected in this survey. Further, we do not know what would be the consequences for infected women in the future. Nevertheless, our findings could raise awareness and contribute to early recognition of these infections, initiation of effective treatment and prevention strategies as well as to further surveys involving larger groups of women.

\section{Acknowledgements}

This work was supported by the European Territorial Cooperation Programme Greece-Bulgaria 2007-2013, co-funded by the EU and National Funds of Greece and Bulgaria (Subsidy contract №: B2.13.01/ 01.04.2012).

\section{Conflicts of Interests}

None declared

\section{REFERENCES}

1. Khenchouche A, Sadouki N, Boudriche A, Houali K, Graba A, Ooka $\mathrm{T}$, et al. Human papillomavirus and Epstein-Barr virus co-infection in cervical carcinoma in Algerian women. Virol J. 2013 Nov 19;10:340. doi: 10.1186/1743-422X-10-340.

2. Smith JS, Herrero R, Bosetti C, Muñoz N, Bosch FX, Eluf-Neto J, et al.; International Agency for Research on Cancer (IARC) Multicentric Cervical Cancer Study Group. Herpes simplex virus-2 as a human papillomavirus cofactor in the etiology of invasive cervical cancer. J Natl Cancer Inst. 2002 Nov 6;94(21):1604-13.

3. Szostek S, Zawilinska B, Kopec J, Kosz-Vnenchak M. Herpesviruses as possible cofactors in HPV-16-related oncogenesis. Acta Biochim Pol. 2009;56(2):337-42

4. Shikova E, Todorova I, Ganchev G, Kouseva-Dragneva V, KalaschevaZaimova P. Prevalence of human papillomavirus infection among female sex workers in Bulgaria. Int J STD AIDS. 2011 May;22(5):278-80.

5. Poljak M, Seme K, Maver PJ, Kocjan BJ, Cuschieri KS, Rogovskaya SI, et al. Human papillomavirus prevalence and type-distribution, cervical cancer screening practices and current status of vaccination implementation in Central and Eastern Europe. Vaccine. 2013 Dec 31;31 Suppl 7:H59-70.

6. Abba MC, Golijow CD. Herpes simplex virus genotyping: multiple optional PCR-based RFLP systems and a non-isotopic single-strand conformation polymorphism method. J Virol Methods. 2004 Jun 1;118(1):73-6

7. Dinc B, Bozdayi G, Biri A, Kalkanci A, Dogan B, Bozkurt N, et al Molecular detection of cytomegalovirus, herpes simplex virus 2, human papillomavirus 16-18 in Turkish pregnants. Braz J Infect Dis. 2010 NovDec;14(6):569-74.

8. Pereira VS, Moizeis RN, Fernandes TA, Araújo JM, Meissner RV, Fernandes JV. Herpes simplex virus type 1 is the main cause of genital herpes in women of Natal, Brazil. Eur J Obstet Gynecol Reprod Biol. 2012 Apr;161(2):190-3.
9. Berntsson M, Dubicanac L, Tunbäck P, Ellström A, Löwhagen GB, Bergström T. Frequent detection of cytomegalovirus and Epstein-Barr virus in cervical secretions from healthy young women. Acta Obstet Gynecol Scand. 2013 Jun;92(6):706-10.

10. McIver CJ, Rismanto N, Smith C, Naing ZW, Rayner B, Lusk MJ, et al. Multiplex PCR testing detection of higher-than-expected rates of cervical mycoplasma, ureaplasma, and trichomonas and viral agent infections in sexually active australian women. J Clin Microbiol. 2009 May;47(5):1358-63.

11. Bradshaw CS, Tabrizi SN, Read TR, Garland SM, Hopkins CA, Moss LM, et al. Etiologies of nongonococcal urethritis: bacteria, viruses, and the association with orogenital exposure. J Infect Dis. 2006 Feb $1 ; 193(3): 336-45$

12. Forward KR, Lee SH. Predominance of herpes simplex virus type 1 from patients with genital herpes in Nova Scotia. Can J Infect Dis. 2003 Mar;14(2):94-6.

13. Kortekangas-Savolainen O, Vuorinen T. Trends in herpes simplex virus type 1 and 2 infections among patients diagnosed with genital herpes in a Finnish sexually transmitted diseases clinic, 1994-2002. Sex Transm Dis. 2007;34(1):37-40.

14. Garceau R, Leblanc D, Thibault L, Girouard G, Mallet M. Herpes simplex virus type 1 is the leading cause of genital herpes in New Brunswick. Can J Infect Dis Med Microbiol. 2012 Spring;23(1):15-8.

15. Pereira VS, Moizeis RN, Fernandes TA, Araújo JM, Meissner RV, Fernandes JV. Herpes simplex virus type 1 is the main cause of genital herpes in women of Natal, Brazil. Eur J Obstet Gynecol Reprod Biol. 2012 Apr;161(2):190-3.

16. Pebody RG, Andrews N, Brown D, Gopal R, De Melker H, François $\mathrm{G}$, et al. The seroepidemiology of herpes simplex virus type 1 and 2 in Europe. Sex Transm Infect. 2004 Jun;80(3):185-91.

17. Arbyn M, Antoine J, Valerianova Z, Mägi M, Stengrevics A, Smailyte G, e al. Trends in cervical cancer incidence and mortality in Bulgaria, Estonia, Latvia, Lithuania and Romania. Tumori. 2010 Jul-Aug;96(4):517-23.

18. Silver MI, Paul P, Sowjanya P, Ramakrishna G, Vedantham H, Kalpana $\mathrm{B}$, et al. Shedding of Epstein-Barr virus and cytomegalovirus from the genital tract of women in a periurban community in Andhra Pradesh, India. J Clin Microbiol. 2011 Jul;49(7):2435-9.

19. Broccolo F, Cassina G, Chiari S, Garcia-Parra R, Villa A, Leone BE, et al. Frequency and clinical significance of human beta-herpesviruses in cervical samples from Italian women. J Med Virol. 2008 Jan;80(1):14753.

20. Taylor Y, Melvin WT, Sewell HF, Flannelly G, Walker F. Prevalence of Epstein-Barr virus in the cervix. J Clin Pathol. 1994 Jan;47(1):92-3.

21. Gradilone A, Vercillo R, Napolitano M, Cardinali G, Gazzaniga P, Silvestri I, et al. Prevalence of human papillomavirus, cytomegalovirus, and Epstein-Barr virus in the cervix of healthy women. J Med Virol. 1996 Sep;50(1):1-4.

22. Thomas R, Macsween KF, McAulay K, Clutterbuck D, Anderson R, Reid $\mathrm{S}$, et al. Evidence of shared Epstein-Barr viral isolates between sexual partners, and low level EBV in genital secretions. J Med Virol. 2006 Sep;78(9):1204-9.

23. Cheng SX, Chapman MS, Margesson LJ, Birenbaum D. Genital ulcers caused by Epstein-Barr virus. J Am Acad Dermatol. 2004 Nov;51(5):8246.

24. Halvorsen JA, Brevig T, Aas T, Skar AG, Slevolden EM, Moi H. Genita ulcers as initial manifestation of Epstein-Barr virus infection: two new cases and a review of the literature. Acta Derm Venereol. 2006;86(5):43942 .

Received February 2, 2015 Accepted in revised form February 25, 2016 